\title{
Blood Pressure Elevation Associated with Topical Prostaglandin F2 $\alpha$ Analogs: An Analysis of the Different Spontaneous Adverse Event Report Databases
}

\author{
Katsuhiro Ohyama,* Haruna Kawakami, and Michiko Inoue \\ Education Center for Experiential Pharmacy Practice, School of Pharmacy, Tokyo University of Pharmacy and Life \\ Science; 1432-1 Horinouchi, Hachioji, Tokyo 192-0392, Japan. \\ Received October 28, 2016; accepted February 19, 2017
}

Topical prostaglandin F2 $\alpha$ (PGF2 $\alpha$ ) analogs are widely used as the first line of therapy for glaucoma. Systemic PGF2 $\alpha$ is suggested to increase blood pressure. Some ophthalmic formulations with $\beta$-receptor blocking or $\alpha$-receptor stimulating actions are reported to cause systemic adverse events such as a decrease in heart rate and blood pressure. The objective of this study was to evaluate the association between topical PGF2 $\alpha$ analogs and blood pressure elevation. We analyzed the reports obtained from the Food and Drug Administration Adverse Event Reporting System (FAERS) database from the first quarter of 2004 until the end of 2015 and the Japanese Adverse Drug Event Report (JADER) database from April 2004 to January 2016 for signal detection using reporting odds ratio (ROR), a method of disproportionality analyses. Signals are considered significant if the ROR estimates and lower bound of the 95\% confidence interval (CI) exceed 1. Preferred terms in the Medical Dictionary for Regulatory Activities were utilized to define blood pressure elevation. A total of 6156081 reports from the FAERS and 351226 reports from the JADER were analyzed. The significant RORs with $95 \%$ CI were calculated to be 1.82 (95\% CI: $1.55-2.13)$ for bimatoprost, 1.69 (95\% CI: 1.53-1.85) for latanoprost, and 2.17 (95\% CI: 1.82-2.59) for travoprost from the FAERS. From the JADER, 5.01 (95\% CI: 1.59-15.8) was calculated for bimatoprost and 8.02 (95\% CI: 2.94-21.9) for tafluprost. The resulting data suggest the necessity for further clinical research on blood pressure elevation associated with topical PGF2 $\alpha$ analogs and close monitoring.

Key words prostaglandin F2 $\alpha$ analog; blood pressure elevation; spontaneous reporting database; adverse event; reporting odds ratio

Glaucoma is a progressive, chronic condition prevalent worldwide that causes damage to the optic nerve, resulting in irreversible visual impairment and blindness. Based on the status of the internal drainage system, this condition is divided into two major subtypes i.e., open angle and angle closure. ${ }^{1)}$ Reducing intraocular pressure (IOP) is one of the best ways to prevent the development of glaucoma, although there is a kind of open angle glaucoma in which optic neuropathy occurs without IOP exceeding the normal range. The approximate number of glaucoma patients was 60.5 million in 2010 and is estimated to increase to 79.6 million by $2020{ }^{2)}$

Various kinds of medications are available for glaucoma treatment in the form of eye drops such as prostaglandin analogs, $\beta$-blockers, carbonic anhydrase inhibitors, and $\alpha$-adrenergics, which are either used alone or in combination. Because of their effectiveness and convenience in usage, prostaglandin F $2 \alpha$ (PGF2 $\alpha$ ) analogs are widely used as the first line of therapy in patients with glaucoma. They are thought to act through prostaglandin F (FP) receptor located in the ciliary muscle and the trabecular meshwork. ${ }^{3,4)}$ They lower IOP by increasing the outflow of aqueous humor via the uveoscleral pathway. ${ }^{5,6}$ )

Some studies have reported the ability of PGF $2 \alpha$ to elevate blood pressure. ${ }^{7,8)}$ Although some clinical trials have reported that topical PGF2 $\alpha$ analogs are safe,,$^{9-11)}$ they are thought to cause systemic adverse events. Some examples include ophthalmic timolol or brimonidine, which reduce systemic blood pressure by $\beta$-receptor blocking ${ }^{12-14)}$ or $\alpha$-receptor stimulating actions. $^{15}$

It would be difficult to demonstrate the relationship using an epidemiologic study, since the systemic drug adverse events caused by eye drops are very rare. Therefore, we evaluated the relationship between the increase in blood pressure and PGF $2 \alpha$ IOP lowering agents using different databases, specifically the Food and Drug Administration (FDA) Adverse Event Reporting System (FAERS) and Japanese Adverse Drug Event Report (JADER) databases, which are suitable sources to analyze adverse events. Disproportionality analyses with reporting odds ratios (RORs) were performed to detect safety signals. Comparing the analysis results of reports from the different databases helps to assess the similarities between the drug and adverse events overseas and in Japan. Presumably, this is the first report addressing the association of systemic blood pressure elevation with the topical PGF $2 \alpha$ analogs.

\section{MATERIALS AND METHODS}

Data Source The FAERS is freely available and is the largest public database in the world. It is composed of more than five million reports of spontaneous adverse events from pharmaceutical industries and medical providers, supporting the post-marketing drug-safety monitoring efforts of the FDA. The FAERS database consists of seven data sets: patient demographic and administrative information (DEMO), drug/ biologic information (DRUG), adverse events (REAC), patient outcomes (OUTC), report sources (RPSR), start and end dates of drug therapy (THER), and indications for use/diagnosis (INDI). The JADER database is also obtained freely from the website of Pharmaceuticals and Medical Devices Agency 


\begin{tabular}{|l|c|c|c|}
\hline & $\begin{array}{c}\text { Adverse Drug Event of } \\
\text { Blood Pressure Elevation }\end{array}$ & $\begin{array}{c}\text { Other Adverse } \\
\text { Drug Events }\end{array}$ & Total \\
\hline PGF2 $\alpha$ Analog & $\mathrm{a}$ & $\mathrm{b}$ & $\mathrm{a}+\mathrm{b}$ \\
\hline Other Drugs & $\mathrm{c}$ & $\mathrm{d}$ & $\mathrm{c}+\mathrm{d}$ \\
\hline Total & $\mathrm{a}+\mathrm{c}$ & $\mathrm{b}+\mathrm{d}$ & $\mathrm{a}+\mathrm{b}+\mathrm{c}+\mathrm{d}$ \\
\hline
\end{tabular}

$$
\begin{aligned}
& \mathrm{ROR}=\frac{a \times d}{\mathrm{~b} \times \mathrm{c}} \\
& \mathrm{SE}=\{\log (\mathrm{ROR})\}=\sqrt{\frac{1}{\mathrm{a}}+\frac{1}{\mathrm{~b}}+\frac{1}{\mathrm{c}}+\frac{1}{\mathrm{~d}}} \\
& 95 \% \mathrm{CI}=\exp [\log (\mathrm{ROR}) \pm 1.96 \times \mathrm{SE}\{\log (\mathrm{ROR})\}]
\end{aligned}
$$

Fig. 1. Two-by-Two Contingency Table for Calculating Reporting Odds Ratio and $95 \%$ Confidence Interval Data-Mining Algorithm

Table 1. Generic Names and Brand Names for PGF2 $\alpha$ Analogs in the DrugBank Used in This Study from the FAERS Database

\begin{tabular}{ll}
\hline \hline \multicolumn{1}{c}{ Generic name } & \multicolumn{1}{c}{ Brand name } \\
\hline Bimatoprost & Bimatoprost, Lumigan \\
Latanoprost & Latanoprost, Monoprost, Xalatan \\
Tafluprost & Taflotan, Tafluprost, Saflutan, Zioptan \\
Travoprost & Izba, Travatan, Travatan Z, Travoprost \\
\hline
\end{tabular}

(PMDA), the regulatory authority in Japan. It is composed of over three hundred thousand reports. The database consists of four data sets: patient demographic information (demo), drug information (drug), adverse event (reac), and primary disease (hist).

In this study, four PGF2 $\alpha$ analogs namely bimatoprost, latanoprost, tafluprost, and travoprost were analyzed. Before the analysis of the data from the FAERS, all drug names were changed to their relative generic names using the drug database DrugBank ver. 4.0 because FAERS contains generic names and brand names used in the respective reporting countries (Table 1). Furthermore, no combined formulations (e.g., latanoprost/timolol formulation) were extracted to minimize the effect of another agent for glaucoma.

Definition of Blood Pressure Elevation The adverse events in REAC/reac are based on the medical terminology, as preferred terms (PTs), in the Medical Dictionary for Regulatory Activities (MedDRA). The Standardized MedDRA Queries (SMQ) index is a group of the MedDRA terms from one or more "System Organ Class" related to the desired medical state or region of interest, which is widely used to support signal detection. The following ten preferred terms were determined from the Hypertension (coded SMQ 20000147) in SMQ to detect blood pressure elevation in MedDRA ver. 18.0: accelerated hypertension (PT 10000358), blood pressure diastolic increased (PT 10005739), blood pressure increased (PT 10005750), blood pressure systolic increased (PT 10005760), diastolic hypertension (PT 10012758), essential hypertension (PT 10015488), hypertension (PT 10020772), malignant hypertension (PT 10025600), systolic hypertension (PT 10042957), and hypertensive emergency (PT 10058179).

Statistical Analysis RORs, a safety signal index for adverse drug events, were calculated using a data mining algorithm shown in Fig. 1. In this algorithm, the meaning of respective columns is as follows: (a) individuals who were administered the drug of interest (a prostaglandin analog) and experienced hypertension-related adverse events; (b) individuals who were administered the drug of interest, but did not experience hypertension-related adverse events; (c) individuals who were not administered the drug of interest and experienced hypertension-related adverse events; and (d) individuals who were not administered the drug of interest and did not experience hypertension-related adverse events. The signal is considered significant if the lower limit of the $95 \%$ confidence interval (CI) exceeds 1.

Data analyses were performed using JMP 12 (SAS Institute Inc., Cary, NC, U.S.A.).

\section{RESULTS}

The FAERS data from the first quarter of 2004 through the end of 2015 were downloaded from the FDA website, containing 7561254 reports. Following the recommendation of the FDA, we deleted redundant numbers to apply the latest case identification number, resulting in a total of 6156081 reports that were adopted for this study. The JADER data from April 2004 to January 2016 were downloaded from the PMDA website, containing 378532 reports. After excluding incomplete age and sex data, 351226 reports were utilized for analysis.

In the analysis of the FAERS database, a total of 5233 reports were extracted for bimatoprost, 16064 for latanoprost, 655 for tafluprost, and 3656 for travoprost. The hypertensionassociated adverse events were 154, 439, 15, and 128, respectively (Table 2). The total number of reports for ten PTs related to Hypertension in SMQ was 101107. The RORs with 95\% CI for the above-mentioned prostaglandin analogs were calculated to be 1.82 (1.55-2.13), 1.69 (1.53-1.85), 1.40 (0.84-2.34), and 2.17 (1.82-2.59), respectively (Table 2$)$. In the analysis of the JADER database, a total of 99 reports were extracted for bimatoprost, 493 for latanoprost, 84 for tafluprost, and 106 for travoprost. The hypertension-associated adverse events were $3,5,4$, and 2 , respectively (Table 2). The total number of reports for ten PTs related to 'Hypertension' in SMQ was 2179. The RORs with $95 \%$ CI for the above-mentioned prostaglandin analogs were calculated to be 5.01 (1.59-15.8), 1.64 (0.68-4.00), 8.02 (2.94-21.9), and 3.08 (0.76-12.5), respectively (Table 2).

\section{DISCUSSION}

Clinical trials are performed with subjects having similar demographics including age, sex, and co-administered drugs. 
Table 2. Signal Detection for Association between PGF2 $\alpha$ Analogs and Blood Pressure Elevation

\begin{tabular}{|c|c|c|c|c|c|c|}
\hline Data source & Drug & Number of cases & $\begin{array}{l}\text { Number of } \\
\text { non-cases }\end{array}$ & $\begin{array}{l}\text { Total number of } \\
\text { reports }\end{array}$ & ROR & $95 \% \mathrm{CI}$ \\
\hline \multirow[t]{4}{*}{ FAERS } & Bimatoprost & 154 & 5079 & 5233 & 1.82 & $1.55-2.13$ \\
\hline & Latanoprost & 439 & 15625 & 16064 & 1.69 & $1.53-1.85$ \\
\hline & Tafluprost & 15 & 640 & 655 & 1.40 & $0.84-2.34$ \\
\hline & Travoprost & 128 & 3528 & 3656 & 2.17 & $1.82-2.59$ \\
\hline \multirow[t]{4}{*}{ JADER } & Bimatoprost & 3 & 96 & 99 & 5.01 & $1.59-15.8$ \\
\hline & Latanoprost & 5 & 488 & 493 & 1.64 & $0.68-4.00$ \\
\hline & Tafluprost & 4 & 80 & 84 & 8.02 & $2.94-21.9$ \\
\hline & Travoprost & 2 & 104 & 106 & 3.08 & $0.76-12.5$ \\
\hline
\end{tabular}

ROR: reporting odds ratio. $95 \% \mathrm{CI}$ : $95 \%$ confidence interval.

However, in clinical practice, patients receive medications for various diseases and experience adverse drug events that were not reported in clinical studies. In the current study, we used the FAERS and JADER database to detect the association between systemic blood pressure elevation and topical PGF2 $\alpha$ analogs.

The FP receptor is abundantly expressed in the kidney ${ }^{16,17)}$ and plays a role in water and electrolyte homeostasis. ${ }^{18)}$ In addition, PGF $2 \alpha$ stimulates renin release from juxtaglomerular granular cells through the FP receptor, causing an increase in blood pressure by activating the renin-angiotensin-aldosterone system. ${ }^{7)}$ Moreover, a case report suggested the hypertensive response of PGF $2 \alpha$ injected regionally into the myometrium for the purpose of uterine constriction. ${ }^{8)}$ Therefore, topical PGF $2 \alpha$ can also be clinically relevant against systemic adverse events if the dose is sufficient to maintain the pharmacological activity.

Topical timolol maleate is a $\beta$-blocker and a candidate for glaucoma medication. Previous reports on ophthalmic timolol suggest its effects on blood pressure and heart rate in spite of low plasma concentration ${ }^{12-14)}$ mainly during night time. It is contraindicated in patients with bronchial asthma, severe chronic obstructive pulmonary disease, and sinus bradycardia. ${ }^{19)}$ Furthermore, ophthalmic brimonidine decreased systemic blood pressure. ${ }^{15)}$ Hence, even when topically applied, it is postulated to exert its pharmacological effect systemically, provided sufficient amount of drug is absorbed via nasopharyngeal mucosa into the circulation.

There are insufficient studies on the effect of PGF $2 \alpha$ eye drops on systemic blood pressure. Recently, Oddone et al. showed that bimatoprost $0.01 \%$, which was developed to decrease local adverse effects including conjunctival hyperemia, eyelash growth, and skin pigmentation, ${ }^{20)}$ did not alter the nocturnal blood pressure after 8-week clinical trials. ${ }^{9)}$ Bimatoprost-related blood pressure elevation was not examined in some clinical trials for $0.03 \%$ bimatoprost. $^{21,22)}$ The results of these clinical trials are not in agreement with those of our study, likely because of the following. First, data for bimatoprost $0.01 \%$ might not be sufficient to show the effect since FAERS data includes not only $0.01 \%$ but also $0.03 \%$ bimatoprost formulations, and $0.03 \%$ bimatoprost accounts for the majority of FAERS data. Second, diluted bimatoprost might not be enough to elevate blood pressure primarily regulated by the parasympathetic nerve system at night. The high blood pressure condition of the patient cited in the FAERS database must have been found in the daytime, suggesting that the sympathetic nerve system is superior. According to the circadian rhythm, it is unlikely that the blood pressure increases at night, especially if endogenous vasopressors from the renin-angiotensin-aldosterone system that are involved in blood pressure elevation upon stimulation by PGF $2 \alpha$ analogs were released in the daytime.

Population-based studies revealed a positive correlation between high blood pressure and IOP. ${ }^{23,24)}$ However, the actual change in IOP due to elevation of blood pressure is small. Although some clinical studies revealed that systemic blood pressure elevation increases susceptibility to glaucoma, ${ }^{25,26)}$ other epidemiological and case-controlled studies suggest the protective function of systemic blood pressure elevation in glaucoma. ${ }^{27)}$ Moreover, some studies reported a significant risk of systemic hypotension in glaucomatous damage, ${ }^{28)}$ while others showed that excessively lowered blood pressure with antihypertensive medications increases the risk for glaucoma. ${ }^{29)}$ Thus, evidence for the influence of blood pressure on glaucoma remains controversial.

Owing to the difficulty of the detection of the picogram order's drug disposition, the pharmacokinetic profiles for most of the topical PGF2 $\alpha$ analogs remain unelucidated. ${ }^{30-33)}$ According to the description on their prescribing information, it takes only $10-30 \mathrm{~min}$ for PGF $2 \alpha$ eye drops to attain maximum drug concentration $(18-90 \mathrm{pg} / \mathrm{mL})$ in blood after administration, and the elimination half-lives are calculated to be $17-45 \mathrm{~min} .{ }^{30-33)}$ Nevertheless, is it possible to exert hypertensive activity on the whole body with a transient existence in the systemic circulation? Characteristics of benidipine, a dihydropyridine-derived calcium channel blocker that has a prolonged action without correlations with plasma concentration, could address this question. Benidipine is used once daily, and is absorbed rapidly after an oral dose to humans, reaching maximum drug concentration at about $1 \mathrm{~h} .{ }^{34)}$ Elimination halflife from the plasma is, depending on the dose, reported to be 1-2h, suggesting rapid elimination from plasma. ${ }^{34)}$ Despite a short systemic circulation, why does it have a long-lasting activity through $24 \mathrm{~h}$ ? The concept of the "membrane approach," which is a cell membrane-based approach involving prolonged retention at the binding site, ${ }^{35)}$ is generally accepted and seems to be applicable to benidipine. This concept can clearly explain its strong and long-lasting activity and could apply to PGF $2 \alpha$ analogs. It is said that this property seems to be associated with its high affinity for cell membranes, ${ }^{36}$ ) and the water-to-octanol partition coefficient $\left(\log P_{\mathrm{ow}}\right)$ is available as an index. The partition coefficient of benidipine has been reported to be 3.79 using the flask-shaking method. ${ }^{36}$ ) In accordance with the product interview forms, the partition 
coefficient of PGF2 $\alpha$ analogs are 4.3 for latanoprost, 4.5-4.6 for tafluprost, and $3<$ for travoprost (no description for bimatoprost). Moreover, they are partially distributed through the nasopharyngeal mucosa to the whole body without being metabolized by the hepatic enzyme, indicating the very high liposolubility. Hence, these suggest approximate characteristics and the possibility of adaption to PGF $2 \alpha$ analogs.

In comparing the analysis results of reports from the FAERS and the JADER, it becomes possible to grasp the relationship between the drug, adverse event, and expression tendency both overseas and in Japan. In this analysis, significant signals were detected in bimatoprost, latanoprost, and travoprost from the FAERS database that were in contrast to those detected in bimatoprost and tafluprost from the JADER database (Table 2). With regards to the difference in the results, the possible contributing factors are as follows. First, in each database, the difference in scale in the number of the reports could have effects on the range of the $95 \%$ CI. Therefore, it is possible that signal detection would be difficult because of the wide range of the $95 \%$ CI in the JADER, with comparatively few reports. Second, the FAERS database consists of reports from various countries, including all United States reports and serious/unexpected reports from European Countries, ${ }^{37)}$ and less than $10 \%$ are from Japan. On the other hand, the JADER database is composed of only domestic reports. It is said that ethnic differences, especially between East Asians and Caucasians, in drug responses are caused not only by intrinsic factors such as genetic differences (genetic polymorphism of metabolic enzymes or transporters) or differences in body weight, but also by extrinsic factors such as environmental differences (diet, habits, climate, etc.) ${ }^{38)}$ Therefore, there is a possibility that the interethnic variabilities may be related to the differences in the analysis results from two databases.

The ROR is a widely used data mining method for detecting signals for drugs, which can be considered as a relative risk. ${ }^{39}$ The level of the odds ratio, however, is of less importance but it provides an indication of the degree of disproportionality. ${ }^{40)}$ An analysis utilizing a spontaneous adverse event reporting system has a lot of benefits. It reflects the drug use in a 'real-world' population of patients with various diseases with co-administered drugs. Further, it is an effective way to detect unknown or extremely rare adverse drug events. Analysis results must be evaluated owing to the limitations in the quality and scope of databases. Databases contain certain shortcomings, such as reporting bias, missing or misspelled data, and lack of information on patients' habits (e.g. smoking), occupational risks, underlying diseases, or comorbidities. ${ }^{41)}$

In the present study, we evaluated the relationship between blood pressure elevation and topical PGF $2 \alpha$ analogs using the FAERS and the JADER databases. Our results suggest the necessity for further clinical research and close surveillance.

Conflict of Interest The authors declare no conflict of interest.

\section{REFERENCES AND NOTES}

1) Davis BM, Crawley L, Pahlitzsch M, Javaid F, Cordeiro MF. Glaucoma: the retina and beyond. Acta Neuropathol., 132, 807-826 (2016).

2) Quigley HA, Broman AT. The number of people with glaucoma worldwide in 2010 and 2020. Br. J. Ophthalmol., 90, 262-267 (2006).

3) Sharif NA, Kelly CR, Crider JY. Agonist activity of bimatoprost, travoprost, latanoprost, unoprostone isopropyl ester and other prostaglandin analogs at the cloned human ciliary body FP prostaglandin receptor. J. Ocul. Pharmacol. Ther., 18, 313-324 (2002).

4) Sharif NA, Kelly CR, Crider JY. Human trabecular meshwork cell responses induced by bimatoprost, travoprost, unoprostone, and other FP prostaglandin receptor agonist analogues. Invest. Ophthalmol. Vis. Sci., 44, 715-721 (2003).

5) Griffin BW, Williams GW, Crider JY, Sharif NA. FP prostaglandin receptors mediating inositol phosphates generation and calcium mobilization in Swiss 3T3 cells: a pharmacological study. J. Pharmacol. Exp. Ther., 281, 845-854 (1997).

6) Hellberg MR, Sallee VL, McLaughlin MA, Sharif NA, Desantis L, Dean TR, Zinke PW. Preclinical efficacy of travoprost, a potent and selective FP prostaglandin receptor agonist. J. Ocul. Pharmacol. Ther., 17, 421-432 (2001).

7) $\mathrm{Yu} \mathrm{Y,} \mathrm{Lucitt} \mathrm{MB,} \mathrm{Stubbe} \mathrm{J,} \mathrm{Cheng} \mathrm{Y,} \mathrm{Friis} \mathrm{UG,} \mathrm{Hansen} \mathrm{PB,} \mathrm{Jensen}$ BL, Smyth EM, FitzGerald GA. Prostaglandin F2alpha elevates blood pressure and promotes atherosclerosis. Proc. Natl. Acad. Sci. U.S.A., 106, 7985-7990 (2009).

8) Ono K, Nakayama K, Kudo I, Okutu Y. Acute hypertensive response and arrhythmia probably due to prostaglandin F2 $\alpha$ during cesarean section, two cases report. J. Jpn. Clin. Anesth., 10, 95-98 (1990)

9) Oddone F, Rossetti L, Tanga L, Berardo F, Ferrazza M, Michelessi M, Roberti G, Manni G, Centofanti M. Effects of topical bimatoprost $0.01 \%$ and timolol $0.5 \%$ on circadian IOP, blood pressure and perfusion pressure in patients with glaucoma or ocular hypertension: A randomized, double masked, placebo-controlled clinical trial. PLoS ONE, 10, e0140601 (2015).

10) Inan UU, Ermis SS, Orman A, Onrat E, Yucel A, Ozturk F, Asagidag A, Celik A. The comparative cardiovascular, pulmonary, ocular blood flow, and ocular hypotensive effects of topical travoprost, bimatoprost, brimonidine, and betaxolol. J. Ocul. Pharmacol. Ther., 20, 293-310 (2004)

11) Waldock A, Snape J, Graham CM. Effects of glaucoma medications on the cardiorespiratory and intraocular pressure status of newly diagnosed glaucoma patients. Br. J. Ophthalmol., 84, 710-713 (2000).

12) Nieminen $T$, Uusitalo H, Turjanmaa V, Bjärnhall G, Hedenström H, Mäenpää J, Ropo A, Heikkilä P, Kähönen M. Association between low plasma levels of ophthalmic timolol and haemodynamics in glaucoma patients. Eur. J. Clin. Pharmacol., 61, 369-374 (2005).

13) Hayreh SS, Podhajsky P, Zimmerman MB. Beta-blocker eyedrops and nocturnal arterial hypotension. Am. J. Ophthalmol., 128, 301309 (1999).

14) Costagliola $C$, Parmeggiani F, Virgili G, Lamberti G, Incorvaia C, Perri P, Campa C, Sebastiani A. Circadian changes of intraocular pressure and ocular perfusion pressure after timolol or latanoprost in Caucasians with normal-tension glaucoma. Graefes Arch. Clin. Exp. Ophthalmol., 246, 389-396 (2008).

15) Quaranta L, Gandolfo F, Turano R, Rovida F, Pizzolante T, Musig A, Gandolfo E. Effects of topical hypotensive drugs on circadian IOP, blood pressure, and calculated diastolic ocular perfusion pressure in patients with glaucoma. Invest. Ophthalmol. Vis. Sci., 47, 2917-2923 (2006).

16) Abramovitz M, Adam M, Boie Y, Grygorczyk R, Rushmore TH, Nguyen T, Funk CD, Bastien L, Sawyer N, Rochette C, Slipetz DM, Metters KM, Abramovitz M, Adam M, Boie Y, Grygorczyk R, Rushmore TH, Nguyen T, Funk CD, Bastien L, Sawyer N, Rochette C. Human prostanoid receptors: cloning and characterization. Adv. Prostaglandin Thromboxane Leukot. Res., 23, 499-504 (1995).

17) Sugimoto Y, Hasumoto K, Namba T, Irie A, Katsuyama M, Negishi M, Kakizuka A, Narumiya S, Ichikawa A. Cloning and expression of a cDNA for mouse prostaglandin F receptor. J. Biol. Chem., 269, 
1356-1360 (1994).

18) Saito O, Guan Y, Qi Z, Davis LS, Kömhoff M, Sugimoto Y, Narumiya S, Breyer RM, Breyer MD. Expression of the prostaglandin F receptor (FP) gene along the mouse genitourinary tract. Am. J. Physiol. Renal Physiol., 284, F1164-F1170 (2003).

19) Prescribing information for Timolol GFS (timolol maleate ophthalmic gel formingsolution) 0.25 and $0.5 \%, 2007$.

20) Katz LJ, Cohen JS, Batoosingh AL, Felix C, Shu V, Schiffman RM. Twelve-month, randomized, controlled trial of bimatoprost 0.01 , 0.0125 , and $0.03 \%$ in patients with glaucoma or ocular hypertension. Am. J. Ophthalmol., 149, 661-671.e1 (2010).

21) Kammer JA, Katzman B, Ackerman SL, Hollander DA. Efficacy and tolerability of bimatoprost versus travoprost in patients previously on latanoprost: a 3-month, randomised, masked-evaluator, multicentre study. Br. J. Ophthalmol., 94, 74-79 (2010).

22) Wirta D, Vandenburgh AM, Weng E, Whitcup SM, Kurstjens S, Beddingfield FC 3rd. Long-term safety evaluation of bimatoprost ophthalmic solution $0.03 \%$ : a pooled analysis of six double-masked, randomized, active-controlled clinical trials. Clin. Ophthalmol., 5, 759-765 (2011)

23) Bonomi L, Marchini G, Marraffa M, Bernardi P, Morbio R, Varotto A. Vascular risk factors for primary open angle glaucoma: the Egna-Neumarkt Study. Ophthalmology, 107, 1287-1293 (2000).

24) Klein BE, Klein R, Knudtson MD. Intraocular pressure and systemic blood pressure: longitudinal perspective: the Beaver Dam Eye Study. Br. J. Ophthalmol., 89, 284-287 (2005).

25) Hulsman CA, Vingerling JR, Hofman A, Witteman JC, de Jong PT. Blood pressure, arterial stiffness, and open-angle glaucoma: the Rotterdam study. Arch. Ophthalmol., 125, 805-812 (2007).

26) Mitchell P, Lee AJ, Rochtchina E, Wang JJ. Open-angle glaucoma and systemic hypertension: the blue mountains eye study. J. Glaucoma, 13, 319-326 (2004).

27) Collignon N, Dewe W, Guillaume S, Collignon-Brach J. Ambulatory blood pressure monitoring in glaucoma patients. The nocturnal systolic dip and its relationship with disease progression. Int. Ophthalmol., 22, 19-25 (1998).

28) Kaiser HJ, Flammer J. Systemic hypotension: a risk factor for glaucomatous damage? Ophthalmologica, 203, 105-108 (1991).

29) Topouzis F, Coleman AL, Harris A, Jonescu-Cuypers C, Yu F, Mavroudis L, Anastasopoulos E, Pappas T, Koskosas A, Wilson MR. Association of blood pressure status with the optic disk structure in non-glaucoma subjects: the Thessaloniki eye study. Am. J. Ophthalmol., 142, 60-67 (2006).
30) Prescribing information for XALATAN ${ }^{\circledR}$ (latanoprost ophthalmic solution) $0.005 \%, 2014$.

31) Prescribing information for TRAVATAN $Z^{\circledR}$ (travoprost ophthalmic solution) $0.004 \%, 2011$.

32) Prescribing information for ZIOPTAN ${ }^{\mathrm{TM}}$ (tafluprost ophthalmic solution) $0.0015 \%, 2013$.

33) Prescribing information for LUMIGAN ${ }^{\circledR}$ (bimatoprost ophthalmic solution) $0.01 \%, 2014$.

34) Uji Y, Sugimoto T, Kobayashi H, Kobayashi S. Phase I clinical study of benidipine hydrochloride (KW-3049). Jpn. Pharmacol. Ther., 18, S689-S702 (1990).

35) Rhodes DG, Sarmiento JG, Herbette LG. Kinetics of binding of membrane-active drugs to receptor sites. Diffusion-limited rates for a membrane bilayer approach of 1,4-dihydropyridine calcium channel antagonists to their active site. Mol. Pharmacol., 27, 612-623 (1985).

36) Yao K, Nagashima K, Miki H. Pharmacological, pharmacokinetic, and clinical properties of benidipine hydrochloride, a novel, longacting calcium channel blocker. J. Pharmacol. Sci., 100, 243-261 (2006).

37) Poluzzi E, Raschi E, Godman B, Koci A, Moretti U, Kalaba M, Wettermark B, Sturkenboom M, De Ponti F. Pro-arrhythmic potential of oral antihistamines (H1): combining adverse event reports with drug utilization data across Europe. PLOS ONE, 10, e0119551 (2015).

38) Hasunuma $T$, Tohkin M, Kaniwa N, Jang IJ, Yimin C, Kaneko M, Saito Y, Takeuchi M, Watanabe H, Yamazoe Y, Uyama Y, Kawai S. Absence of ethnic differences in the pharmacokinetics of moxifloxacin, simvastatin, and meloxicam among three East Asian populations and Caucasians. Br. J. Clin. Pharmacol., 81, 1078-1090 (2016).

39) Rothman KJ, Lanes S, Sacks ST. The reporting odds ratio and its advantages over the proportional reporting ratio. Pharmacoepidemiol. Drug Saf., 13, 519-523 (2004).

40) Van Puijenbroek EP, Egberts AC, Meyboom RH, Leufkens HG. Signalling possible drug-drug interactions in a spontaneous reporting system: delay of withdrawal bleeding during concomitant use of oral contraceptives and itraconazole. Br. J. Clin. Pharmacol., 47, 689-693 (1999).

41) Yue Z, Shi J, Jiang P, Sun H. Acute kidney injury during concomitant use of valacyclovir and loxoprofen: detecting drug-drug interactions in a spontaneous reporting system. Pharmacoepidemiol. Drug Saf., 23, 1154-1159 (2014). 